\title{
Variabilidade de isolados de Myrothecium roridum provenientes de meloeiro cultivado no Estado do Rio Grande do Norte
}

\author{
Marissônia A. Noronha ${ }^{1}$, Sami J. Michereff ${ }^{1}$, Priscilla A.A. Moreira ${ }^{1}$, Maria S. Xavier Filha ${ }^{1}$, Rui Sales Jr. ${ }^{2}$ \\ \& Eduardo S.G. Mizubuti ${ }^{3}$ \\ ${ }^{1}$ Universidade Federal Rural de Pernambuco, Departamento de Fitossanidade, 52171-900, Recife, PE, Brasil; ${ }^{2}$ Universidade \\ Federal Rural do Semi-Árido, Departamento de Ciências Florestais, 59625-900, Mossoró, RN, Brasil; ${ }^{3}$ Universidade Federal \\ de Viçosa, Departamento de Fitopatologia, 36570-000, Viçosa, MG, Brasil
}

Autor para correspondência: Sami J. Michereff, e-mail: sami@depa.ufrpe.br

\section{RESUMO}

A variabilidade de 53 isolados de Myrothecium roridum, obtidos de diferentes cultivos de meloeiro (Cucumis melo) do Estado do Rio Grande do Norte, foi estimada com base em variáveis relacionadas à: severidade do cancro-de-mirotécio nas cultivares AF-682 e Orange Flesh, fisiologia do patógeno (taxa de crescimento micelial - TCM - e esporulação - ESP) e sensibilidade ao fungicida fluazinam (ICM). Todos os isolados foram patogênicos às cultivares AF-682 e Orange Flesh, porém, nessa última houve maior discriminação entre isolados, quanto às variáveis mensuradas. A variabilidade entre os isolados foi alta quando se analisaram as variáveis medidas, com exceção de TCM e sensibilidade a fungicidas (todos sensíveis). Não foi verificada correlação significativa da SEV com as demais variáveis. A variação entre isolados dentro de município $(60 \%)$ foi maior que a variação entre municípios. Provavelmente, há alta variabilidade genética nas populações de M. roridum e não foi possível detectar associações entre as variáveis analisadas e localidades amostradas.

Palavras-chave: Cucumis melo, cancro-de-mirotécio, severidade da doença, sensibilidade a fluazinam.

\begin{abstract}
Variability of Myrothecium roridum isolates from cultivated melon in the State of Rio Grande do Norte, Brazil

The variability of 53 isolates of Myrothecium roridum obtained from melon (Cucumis melo) fields in the State of Rio Grande do Norte (Brazil) was estimated based on: severity of Myrothecium stem canker in the cultivars AF-682 and Orange Flesh, the pathogen's physiology (mycelium growth rate - MGR - and sporulation - SP) and its sensitivity to the fungicide fluazinam. All isolates were pathogenic to AF-682 and Orange Flesh; however, better discrimination of pathogen variability was achieved in the latter. Variation among isolates was high when assessing all variables, except for MGR and sensitivity to fungicides (all sensitive). There was no correlation between SEV and any other variables. The variation among isolates within municipalities $(60 \%)$ was higher than the variation among municipalities. There is evidence of high genetic variability in the populations of M. roridum, but no association between the assessed variables and locations was detected. Keywords: Cucumis melo, Myrothecium stem canker, disease severity, sensitivity to fluazinam.
\end{abstract}

\section{INTRODUÇÃO}

No Nordeste brasileiro, a cultura do meloeiro(Cucumis melo L.) encontra condições climáticas excepcionais para o seu desenvolvimento, como temperaturas elevadas e altos níveis de insolação, o que resulta na produção de frutos com elevados teores de sólidos solúveis totais. O maior pólo produtor situa-se no Estado do Rio Grande do Norte (RN), denominado Agropólo Mossoró/Assú, que representa aproximadamente $46 \%$ da área cultivada do país (FNP, 2008).

Nos últimos anos, a expansão da área cultivada, aliada ao cultivo intensivo e contínuo de meloeiro, sem rotação de culturas, tem contribuído para a sobrevivência de patógenos e o aumento de doenças, que vêm causando perdas significativas na produção (Santos \& Pinheiro Neto, 2004). Dentre estas, o cancro-de-mirotécio, causado por Myrothecium roridum Tode, foi detectado em meloeiro pela primeira vez no Brasil em 1991, em Mossoró (Silva et al., 1996) e, desde então, tem ocorrido com freqüência nos plantios da região.

O fungo $M$. roridum possui ampla gama de hospedeiros, sendo capaz de infectar mais de 20 famílias botânicas (Domsch et al., 1980). Além disso, apresenta baixa especificidade por tecido hospedeiro, podendo causar sintomas em várias partes do meloeiro, tais como cancros em hastes e no colo, podridões em frutos e manchas foliares. Os sintomas de cancro-de-mirotécio são mais comuns próximos ao colo e se caracterizam por lesões alongadas, necróticas, que se tornam deprimidas, com posterior formação de estruturas de frutificação do fungo (esporodóquios) de coloração verde-oliva, que são visíveis e abundantes. Quando as lesões no colo surgem na presença de chuvas intensas, ocorre a morte rápida da planta (Bruton, 1996). 
Myrothecium roridum é um habitante natural do solo, podendo sobreviver como saprófita nesse ambiente por longos períodos e em restos culturais de meloeiro (Rego \& Carrijo, 2000; Viana et al., 2001). A sua transmissão por sementes ainda não foi comprovada, embora seja isolado com freqüência das mesmas, afetando a germinação e o crescimento das plântulas (Nguyen et al., 1973; Drake, 1980; Lima et al., 1997). A disseminação dos esporos de $M$. roridum ocorre, principalmente, por respingos de água das chuvas e irrigação (Chitarra \& Meyer, 2004). Fungicidas que atuam em outras doenças foliares poderiam ser efetivos também para o controle das manchas foliares causadas por esse patógeno em meloeiro, mas o controle de cancros no colo e lesões nos frutos é difícil, se não impossível, devido à dificuldade em atingir a superfície-alvo (Bruton, 1996). Além disso, não existem fungicidas registrados no Brasil para o controle de M. roridum em meloeiro (MAPA, 2008).

No desenvolvimento de estratégias de manejo das doenças radiculares do meloeiro, é essencial o conhecimento da variabilidade das populações dos patógenos e dos níveis de resistência do hospedeiro. O sucesso de programas de melhoramento visando a resistência depende do conhecimento sobre a variabilidade do patógeno, motivo pelo qual esse aspecto deve ser investigado antes da seleção de fontes de resistência no hospedeiro (Bruton, 1998).

Do ponto de vista evolutivo, a variabilidade genética das populações é importante por determinar o potencial de adaptação do organismo às diferentes condições sob as quais se encontram. Do ponto de vista epidemiológico, a variabilidade patogênica tem implicações diretas no manejo da doença (McDonald \& Linde, 2002). A existência de variabilidade nas populações de $M$. roridum influencia a estratégia do melhoramento, especialmente na estabilidade e durabilidade da resistência ao cancro-de-mirotécio.

Os estudos envolvendo a variabilidade de $M$. roridum em meloeiro são escassos e empregaram pequeno número de isolados, o que compromete a representatividade dos resultados. Apenas dois estudos foram realizados com variabilidade de M. roridum (Carter, 1980; Lima et al., 1997). Em um deles, conduzido nos Estados Unidos da América, Carter (1980) constatou diferença significativa na virulência de 15 isolados de $M$. roridum inoculados em uma cultivar de meloeiro. No outro estudo, mesma tendência foi registrada por Lima et al. (1997), no Brasil, ao utilizarem seis cultivares de meloeiro e quatro isolados do patógeno. Diante do exposto, este trabalho teve como objetivo investigar a variabilidade em isolados de $M$. roridum provenientes de áreas de plantio de meloeiro localizadas no Agropólo Mossoró/Assú, com base na severidade da doença, características fisiológicas e sensibilidade ao fungicida fluazinam.

\section{MATERIAL E MÉTODOS}

\section{Isolados de Myrothecium roridum}

Foram utilizados 53 isolados de $M$. roridum, obtidos de colos de plantas e frutos de meloeiro com sintomas de cancro-de-mirotécio e podridão-de-cratera, respectivamente, coletados em 2005, em diferentes áreas de plantio do Agropólo Mossoró/Assú (Tabela 1). Os isolados foram depositados na Coleção de Culturas de Fungos Fitopatogênicos "Profa. Maria Menezes"- CMM, da Universidade Federal Rural de Pernambuco (Recife, Pernambuco) As culturas foram preservadas em água destilada e óleo mineral.

\section{Variabilidade dos isolados de Myrothecium roridum baseada na severidade da doença}

Os isolados de M. roridum foram cultivados por 14 dias em placas de Petri contendo meio de cultura batatadextrose-ágar (BDA) e incubados à temperatura de $25 \pm$ $2^{\circ} \mathrm{C}$ sob luminosidade constante. Na preparação do inóculo, foram adicionados $20 \mathrm{ml}$ de água destilada esterilizada em cada placa, efetuada a raspagem das colônias com escova de cerdas macias e filtragem em camada dupla de gaze esterilizada, para a posterior determinação da concentração de conídios com o auxílio de hemacitômetro. A viabilidade dos conídios foi avaliada pelo método de germinação em gota e todos os isolados apresentaram viabilidade superior a $85 \%$. A inoculação foi efetuada em plantas de meloeiro com 22 dias de idade, das cultivares AF-682 e Orange Flesh, cultivadas em solo esterilizado com brometo de metila $\left(\right.$ Bromex $^{\circledR}$, Casa Bernardo Ltda., São Paulo) e mantidas em casa-de-vegetação. As plantas foram feridas na região do colo, a cerca de $10 \mathrm{~mm}$ da superfície do solo, com o auxílio de uma almofada com dois alfinetes entomológicos eqüidistantes em $10 \mathrm{~mm}$, à profundidade de $2 \mathrm{~mm}$. Em seguida, a parte aérea de cada planta foi inoculada pela atomização de $5 \mathrm{ml}$ da suspensão de $3 \times 10^{6}$ conídios $/ \mathrm{ml}$ de cada isolado de $M$. roridum, suplementada com Tween $20(0,1 \%)$, com o auxílio de atomizador DeVilbiss. A testemunha consistiu de seis plantas feridas e atomizadas com água destilada esterilizada. Após a inoculação, as plantas foram mantidas em câmara úmida, consistindo do envolvimento das plantas em sacos de polietileno umedecidos internamente por 36 horas, e posteriormente, deixadas em casa de vegetação. Durante o período de execução do experimento, a temperatura na casade-vegetação foi de $31,1 \pm 8,6^{\circ} \mathrm{C}$ e a umidade relativa de $69,5 \pm 27,6 \%$.

O delineamento experimental utilizado foi em blocos ao acaso com quatro repetições, sendo cada repetição constituída por um vaso com seis plantas, totalizando 24 plantas inoculadas por isolado. A severidade do cancrode-mirotécio foi avaliada em cada planta, aos seis dias após a retirada da câmara úmida, com o auxílio da escala descritiva de notas de 0 a 4, onde: $0=$ sem sintomas; $1=$ lesões no caule de 0,1 a $6,9 \mathrm{~mm} ; 2=$ lesões no caule $>7$ $\mathrm{mm}$, sem esporodóquios; $3=$ lesões no caule $>7 \mathrm{~mm}$, com esporodóquios; e $4=$ morte da planta. $\mathrm{O}$ índice de severidade da doença (SEV) em cada vaso foi calculado de acordo com McKinney (1923), pela expressão: $\mathrm{SEV}=\left[\sum\right.$ (grau da escala $\mathrm{x}$ freqüência)/(número total de unidades $\mathrm{x}$ grau máximo da escala)]x100, utilizando-se os dados de severidade obtidos com a escala de notas. 
Variabilidade dos isolados de Myrothecium roridum baseada em características fisiológicas

Cada isolado do patógeno foi avaliado quanto à taxa de crescimento micelial (TCM) e esporulação (ESP). Para obtenção da TCM, discos de cultura dos isolados de M. roridum obtidos BDA com $5 \mathrm{~mm}$ de diâmetro, com 14 dias de idade, foram transferidos para o centro de placas de Petri contendo BDA. As placas foram mantidas a $25 \pm$
$1{ }^{\circ} \mathrm{C}$, sob alternância luminosa ( $12 \mathrm{~h}$ claro/12 h escuro). $\mathrm{O}$ delineamento experimental foi inteiramente casualizado, com cinco repetições, sendo cada repetição constituída por uma placa. O crescimento micelial de cada isolado foi avaliado aos sete e 14 dias de incubação, pela mensuração do diâmetro da colônia em dois sentidos diametralmente opostos e cálculo da média por placa. A TCM ( $\mathrm{mm} / \mathrm{dia})$ foi calculada pela expressão: TCM $=\left(\mathrm{y}_{14}-\mathrm{y}_{7}\right) / \mathrm{d}$, onde $\mathrm{y}_{7}$ e $\mathrm{y}_{14}$ são

TABELA 1 - Valores de severidade do cancro-de-mirotécio nas cultivares de meloeiro AF-682 e Orange Flesh, de características fisiológicas e de sensibilidade ao fungicida fluazinam mensurados para estimar a variabilidade de isolados de Myrothecium roridum procedentes de diferentes áreas de plantio de meloeiro do Estado do Rio Grande do Norte

\begin{tabular}{|c|c|c|c|c|c|c|}
\hline \multirow[t]{2}{*}{ Isolado ${ }^{1}$} & \multirow[t]{2}{*}{ Município de oigem } & \multicolumn{2}{|c|}{ Severidade $\left[\operatorname{SEV}(\%)^{2}\right]$} & \multicolumn{2}{|c|}{ Características fisiológicas } & \multirow{2}{*}{$\begin{array}{l}\text { Fluazinam } \\
\text { ICM (\%) }\end{array}$} \\
\hline & & AF-682 & Orange Flesh & $\begin{array}{c}\mathbf{T C M}^{3} \\
(\mathrm{~mm} / \mathrm{dia})\end{array}$ & $\begin{array}{c}\text { ESP }^{4} \\
\left(\times 10^{5} \operatorname{con} / \mathrm{ml}\right)\end{array}$ & \\
\hline CMM-607 & Baraúna & $38,5 \mathrm{e}^{6}$ & $2,1 \mathrm{~h}$ & $5,4 \mathrm{a}$ & $10,9 \mathrm{~d}$ & $70,3 \mathrm{a}$ \\
\hline CMM-608 & Baraúna & $41,7 \mathrm{e}$ & $34,4 \mathrm{f}$ & $4,9 \mathrm{a}$ & $21,0 \mathrm{~d}$ & $75,2 \mathrm{a}$ \\
\hline CMM-609 & Mossaró & $55,2 \mathrm{~d}$ & $90,6 \mathrm{a}$ & $5,0 \mathrm{a}$ & $29,1 \mathrm{c}$ & $60,9 \mathrm{~b}$ \\
\hline CMM-610 & Baraúna & $53,1 \mathrm{~d}$ & $37,5 \mathrm{e}$ & $5,6 \mathrm{a}$ & $18,6 \mathrm{~d}$ & $70,1 \mathrm{a}$ \\
\hline CMM-611 & Baraúna & $79,2 \mathrm{~b}$ & $17,7 \mathrm{~g}$ & $5,3 \mathrm{a}$ & $22,6 \mathrm{~d}$ & $63,0 \mathrm{~b}$ \\
\hline CMM-612 & Mossoró & $86,5 \mathrm{a}$ & $33,3 \mathrm{f}$ & $5,6 \mathrm{a}$ & $43,0 \mathrm{~b}$ & $65,7 \mathrm{~b}$ \\
\hline CMM-613 & Mossoró & $52,1 \mathrm{~d}$ & $28,1 \mathrm{f}$ & $4,8 \mathrm{a}$ & $60,8 \mathrm{~b}$ & $59,1 \mathrm{c}$ \\
\hline CMM-614 & Mossoró & $34,4 \mathrm{e}$ & $24,0 \mathrm{~g}$ & $5,4 \mathrm{a}$ & $60,6 b$ & $63,2 \mathrm{~b}$ \\
\hline CMM-615 & Mossoró & $78,1 \mathrm{~b}$ & $58,3 \mathrm{c}$ & $5,1 \mathrm{a}$ & $31,4 \mathrm{c}$ & $56,5 \mathrm{c}$ \\
\hline CMM-616 & Baraúna & $72,9 \mathrm{~b}$ & $43,8 \mathrm{e}$ & $5,3 \mathrm{a}$ & $45,2 \mathrm{~b}$ & $59,8 \mathrm{c}$ \\
\hline CMM-617 & Baraúna & $61,5 \mathrm{c}$ & $30,2 \mathrm{f}$ & $5,2 \mathrm{a}$ & $50,6 \mathrm{~b}$ & $74,0 \mathrm{a}$ \\
\hline CMM-618 & Baraúna & $78,1 \mathrm{~b}$ & $28,1 \mathrm{f}$ & $5,5 \mathrm{a}$ & $35,5 \mathrm{c}$ & $61,4 \mathrm{~b}$ \\
\hline CMM-619 & Baraúna & $47,9 \mathrm{~d}$ & $24,0 \mathrm{~g}$ & $5,4 \mathrm{a}$ & $4,2 \mathrm{~d}$ & $51,7 \mathrm{c}$ \\
\hline CMM-620 & Baraúna & $62,5 \mathrm{c}$ & $1,0 \mathrm{~h}$ & $5,4 \mathrm{a}$ & $9,2 \mathrm{~d}$ & $70,8 \mathrm{a}$ \\
\hline CMM-625 & Baraúna & $58,3 \mathrm{c}$ & $21,9 \mathrm{~g}$ & $5,1 \mathrm{a}$ & $49,5 \mathrm{~b}$ & $71,2 \mathrm{a}$ \\
\hline CMM-627 & Mossoró & $1,0 \mathrm{f}$ & $0,0 \mathrm{~h}$ & $4,6 \mathrm{a}$ & $9,5 \mathrm{~d}$ & $65,2 \mathrm{~b}$ \\
\hline CMM-628 & Mossoró & $61,5 \mathrm{c}$ & $34,4 \mathrm{f}$ & $5,4 \mathrm{a}$ & $19,4 \mathrm{~d}$ & $71,7 \mathrm{a}$ \\
\hline CMM-630 & Mossoró & $65,6 \mathrm{c}$ & $9,4 \mathrm{~h}$ & $5,5 \mathrm{a}$ & $13,0 \mathrm{~d}$ & $57,4 \mathrm{c}$ \\
\hline CMM-632 & Mossoró & $26,0 \mathrm{e}$ & $58,3 \mathrm{c}$ & $6,0 \mathrm{a}$ & $21,0 \mathrm{~d}$ & 74,2 a \\
\hline CMM-633 & Mossoró & $32,3 \mathrm{e}$ & $29,2 \mathrm{f}$ & $5,6 \mathrm{a}$ & $24,4 \mathrm{c}$ & $61,6 \mathrm{~b}$ \\
\hline CMM-635 & Mossoró & $96,9 \mathrm{a}$ & $36,5 \mathrm{e}$ & $5,5 \mathrm{a}$ & $17,5 \mathrm{~d}$ & $55,9 \mathrm{c}$ \\
\hline CMM-636 & Mossoró & $88,5 \mathrm{a}$ & $40,6 \mathrm{e}$ & $6,0 \mathrm{a}$ & $67,1 \mathrm{~b}$ & $62,5 \mathrm{~b}$ \\
\hline CMM-637 & Mossoró & $55,2 \mathrm{~d}$ & $38,5 \mathrm{e}$ & $5,9 \mathrm{a}$ & $29,2 \mathrm{c}$ & $68,4 \mathrm{a}$ \\
\hline CMM-638 & Mossoró & $69,8 \mathrm{~b}$ & $61,5 \mathrm{c}$ & $5,5 \mathrm{a}$ & $57,0 \mathrm{~b}$ & $66,4 \mathrm{a}$ \\
\hline CMM-639 & Mossoró & $51,0 \mathrm{~d}$ & $86,5 \mathrm{a}$ & $5,4 \mathrm{a}$ & $56,1 \mathrm{~b}$ & $68,4 \mathrm{a}$ \\
\hline CMM-640 & Mossoró & $63,5 \mathrm{c}$ & $44,8 \mathrm{e}$ & $5,0 \mathrm{a}$ & $98,6 \mathrm{a}$ & $61,8 \mathrm{~b}$ \\
\hline CMM-641 & Mossoró & $52,1 \mathrm{~d}$ & $34,4 \mathrm{f}$ & $5,5 \mathrm{a}$ & $52,0 \mathrm{~b}$ & $62,3 \mathrm{~b}$ \\
\hline CMM-642 & Mossoró & $63,5 \mathrm{c}$ & $30,2 \mathrm{f}$ & $5,5 \mathrm{a}$ & $67,0 \mathrm{~b}$ & $71,0 \mathrm{a}$ \\
\hline CMM-643 & Mossoró & $95,8 \mathrm{a}$ & $56,2 \mathrm{c}$ & $4,9 \mathrm{a}$ & $32,2 \mathrm{c}$ & $57,9 \mathrm{c}$ \\
\hline CMM-644 & Mossoró & $70,8 \mathrm{~b}$ & $46,9 \mathrm{~d}$ & $5,6 \mathrm{a}$ & $55,2 \mathrm{~b}$ & $64,6 \mathrm{~b}$ \\
\hline CMM-645 & Mossoró & $58,3 \mathrm{c}$ & 84,4 a & $5,8 \mathrm{a}$ & $42,0 \mathrm{~b}$ & 70,9 a \\
\hline CMM-736 & Baraúna & $61,5 \mathrm{c}$ & $37,5 \mathrm{e}$ & $5,4 \mathrm{a}$ & $28,8 \mathrm{c}$ & 76,0 a \\
\hline CMM-737 & Baraúna & $72,9 \mathrm{~b}$ & $42,7 \mathrm{e}$ & $5,2 \mathrm{a}$ & $31,0 \mathrm{c}$ & $70,0 \mathrm{a}$ \\
\hline CMM-738 & Baraúna & $26,0 \mathrm{e}$ & $28,1 \mathrm{f}$ & $4,9 \mathrm{a}$ & $21,9 \mathrm{~d}$ & $63,7 \mathrm{~b}$ \\
\hline CMM-739 & Baraúna & $61,5 \mathrm{c}$ & $47,9 \mathrm{~d}$ & $5,3 \mathrm{a}$ & $36,6 \mathrm{c}$ & $67,3 \mathrm{a}$ \\
\hline CMM-740 & Baraúna & $77,1 \mathrm{~b}$ & $39,6 \mathrm{e}$ & $4,8 \mathrm{a}$ & $32,1 \mathrm{c}$ & $64,5 \mathrm{~b}$ \\
\hline CMM-741 & Baraúna & $55,2 \mathrm{~d}$ & $36,5 \mathrm{e}$ & $5,6 \mathrm{a}$ & $43,0 \mathrm{~b}$ & 71,1 a \\
\hline CMM-742 & Baraúna & $69,8 \mathrm{~b}$ & $39,6 \mathrm{e}$ & $5,2 \mathrm{a}$ & $31,4 \mathrm{c}$ & $66,0 \mathrm{~b}$ \\
\hline CMM-743 & Baraúna & $63,5 \mathrm{c}$ & $31,2 \mathrm{f}$ & $4,8 \mathrm{a}$ & $31,6 \mathrm{c}$ & $72,1 \mathrm{a}$ \\
\hline CMM-744 & Baraúna & $75,0 \mathrm{~b}$ & $53,1 \mathrm{~d}$ & $5,6 \mathrm{a}$ & $33,5 \mathrm{c}$ & $74,8 \mathrm{a}$ \\
\hline
\end{tabular}




\section{Cont. TABELA 1}

\begin{tabular}{|c|c|c|c|c|c|c|}
\hline CMM-745 & Baraúna & $65,6 \mathrm{c}$ & $47,9 \mathrm{~d}$ & $4,9 \mathrm{a}$ & $32,4 \mathrm{c}$ & $63,9 \mathrm{~b}$ \\
\hline CMM-746 & Baraúna & $84,4 \mathrm{a}$ & $41,7 \mathrm{e}$ & $5,0 \mathrm{a}$ & $30,9 \mathrm{c}$ & $64,9 \mathrm{~b}$ \\
\hline CMM-747 & Baraúna & $74,0 \mathrm{~b}$ & $43,8 \mathrm{e}$ & $5,3 \mathrm{a}$ & $34,1 \mathrm{c}$ & $70,9 \mathrm{a}$ \\
\hline CMM-748 & Baraúna & $61,5 \mathrm{c}$ & $46,9 \mathrm{~d}$ & $5,5 \mathrm{a}$ & $36,5 \mathrm{c}$ & $66,1 \mathrm{~b}$ \\
\hline CMM-749 & Baraúna & $55,2 \mathrm{~d}$ & $47,9 \mathrm{~d}$ & 5,1 a & $37,6 \mathrm{c}$ & $62,7 \mathrm{~b}$ \\
\hline CMM-750 & Baraúna & $50,0 \mathrm{~d}$ & $39,6 \mathrm{e}$ & $5,2 \mathrm{a}$ & $37,6 \mathrm{c}$ & $73,6 \mathrm{a}$ \\
\hline CMM-751 & Baraúna & $57,3 \mathrm{~d}$ & $44,8 \mathrm{e}$ & $5,2 \mathrm{a}$ & $37,0 \mathrm{c}$ & $66,7 \mathrm{~b}$ \\
\hline CMM-761 & Baraúna & $72,9 \mathrm{~b}$ & $57,3 \mathrm{c}$ & $5,0 \mathrm{a}$ & $47,5 \mathrm{~b}$ & $71,2 \mathrm{a}$ \\
\hline CMM-762 & Baraúna & $67,7 \mathrm{c}$ & $51,0 \mathrm{~d}$ & $4,8 \mathrm{a}$ & $59,1 \mathrm{~b}$ & $73,9 \mathrm{a}$ \\
\hline CMM-766 & Baraúna & $87,5 \mathrm{a}$ & $69,8 \mathrm{~b}$ & $4,3 \mathrm{a}$ & $28,0 \mathrm{c}$ & $66,5 \mathrm{~b}$ \\
\hline CMM-767 & Baraúna & $75,0 \mathrm{~b}$ & $65,6 \mathrm{~b}$ & $5,2 \mathrm{a}$ & $3,2 \mathrm{~d}$ & $62,5 \mathrm{~b}$ \\
\hline CMM-768 & Mossoró & $36,5 \mathrm{e}$ & $69,8 \mathrm{~b}$ & $5,6 \mathrm{a}$ & $27,6 \mathrm{c}$ & $61,9 \mathrm{~b}$ \\
\hline CMM-769 & Baraúna & $71,9 \mathrm{~b}$ & $67,7 \mathrm{~b}$ & $5,4 \mathrm{a}$ & $48,6 \mathrm{~b}$ & $72,6 \mathrm{a}$ \\
\hline \multicolumn{7}{|c|}{$\begin{array}{l}{ }^{1} \mathrm{CMM}=\text { código de depósito e número do isolado na Coleção de Culturas de Fungos Fitopatogênicos "Prof. Maria Menezes", da } \\
\text { Universidade Federal Rural de Pernambuco (Recife, Pernambuco). } \\
{ }^{2} \text { Avaliada aos seis dias após a inoculação, com o auxílio de escala de notas de } 0 \text { a } 4 \text {, onde } 0=\text { ausência de sintomas e } 4=\text { morte da } \\
\text { planta, sendo sua média obtida pelo índice de severidade da doença, conforme Mckinney (1923). } \\
{ }^{3} \mathrm{TCM}=\text { taxa absoluta de crescimento micelial em meio BDA sob alternância luminosa, estimada entre } 7 \text { e } 14 \text { dias. } \\
{ }^{4} \mathrm{ESP}=\text { esporulação, avaliada aos } 21 \text { dias de incubação em meio BDA sob alternância luminosa. } \\
\text { a concentração de } 1 \text { ppm. } \\
{ }^{5} \text { Médias originais. Os dados foram transformados em }(\mathrm{x}+0,5)^{1 / 2} \text { para realização da análise de variância. As médias seguidas pela } \\
\text { mesma letra na vertical não diferem entre si (Scott-Knott, 5\%). }\end{array}$} \\
\hline
\end{tabular}

os valores do crescimento micelial observados aos sete e 14 dias e d o intervalo de tempo (7 dias), entre as avaliações.

A ESP foi avaliada aos 21 dias de incubação, pela adição de $20 \mathrm{~mL}$ de água destilada esterilizada em cada placa utilizada para avaliação do crescimento micelial, efetuandose a raspagem das colônias com escovas de cerdas macias e filtragem em camada dupla de gaze, para a posterior estimativa da concentração de conídios com hemacitômetro. Foram efetuadas quatro contagens dos conídios por repetição de cada isolado, obtendo-se a média.

\section{Variabilidade de isolados de Myrothecium roridum baseada na sensibilidade ao fungicida fluazinam}

$\mathrm{Na}$ determinação da sensibilidade dos isolados de M. roridum ao fungicida fluazinam, foi utilizado o método do fungicida incorporado ao meio de cultura. Discos de cultura dos isolados obtidos em BDA com $5 \mathrm{~mm}$ de diâmetro foram transferidos para o centro de placas contendo 15 $\mathrm{mL}$ de BDA suplementado com 1 ppm de fluazinam (Frowncide $500 \mathrm{SC}^{\circledR}, 50 \%$ p.a.; Ishihara, São Paulo, Brasil). A seleção do fungicida e da dosagem se baseou em teste preliminar (dados não publicados), no qual foi avaliado o efeito inibitório de quatro princípios ativos (carbendazin, fluazinam, tebuconazole e tiofanato metílico), que embora sem registro para o controle de doenças do meloeiro (MAPA, 2008), vêem sendo utilizados no Agropólo Mossoró/Assú. A testemunha consistiu na transferência de discos de cultura dos isolados para placas com BDA, sem suplementação com o fungicida. Os isolados foram incubados a $25 \pm 2{ }^{\circ} \mathrm{C}$, sob alternância luminosa ( $12 \mathrm{~h}$ claro/12h escuro). O delineamento experimental foi inteiramente casualizado, com quatro repetições, sendo cada repetição constituída por uma placa. $\mathrm{O}$ crescimento micelial foi mensurado após sete dias de incubação, como descrito anteriormente. Considerando o crescimento máximo verificado na testemunha, foi calculada a porcentagem de inibição do crescimento micelial (ICM) na presença do fungicida em cada placa.

\section{Análises dos dados}

Inicialmente, foi realizada a análise univariada, considerando cada variável separadamente. Nesse caso, os dados de SEV, TCM, ESP e ICM foram transformados em $(x+0,5)^{1 / 2}$ para evitar violações das pressuposições da análise de variância, submetidos à análise de variância e as médias comparadas pelo teste de agrupamento de ScottKnott $(\mathrm{P}=0,05)$, com o programa SAEG 9.0 (Universidade Federal de Viçosa, Viçosa - MG, Brasil, 2005). A correlação entre a severidade nas duas cultivares (SEV), as variáveis fisiológicas (TCM e ESP) e de sensibilidade ao fungicida fluazinam (ICM), foram avaliadas pela análise de correlação de Pearson. Posteriormente, para SEV foi efetuada a análise de variância pelo procedimento PROC MIXED do programa SAS 8.0 (SAS Institute Inc., Cary - NC, USA, 2002), utilizando um modelo linear misto (fatores fixos e aleatórios) em esquema hierárquico ou aninhado ("nested") (Neter et al., 1990). A cultivar foi considerada como fator fixo, enquanto o município de origem dos isolados de M. roridum e os isolados aninhados dentro do município de origem foram considerados como fatores aleatórios. O objetivo foi estimar os componentes de variância e verificar se a interação isolados (município) x cultivar era significativa. Para tal, utilizou-se a estratégia de ajustar um modelo 
completo (com a interação) e um modelo reduzido (sem a interação). A diferença dos valores de resíduo do logaritmo da verossimilhança foi comparada ao valor tabelado de chiquadrado a 1 grau de liberdade (Littel et al., 1996). Usando o modelo completo (com interações), foram estimados os componentes de variância. Posteriormente, foi realizada a análise de boxplots considerando as duas cultivares dentro de cada variável epidemiológica, visando selecionar a cultivar que permitia a detecção de maior variabilidade baseada na localização, dispersão e distância entre as extremidades dos boxes (Peck \& Devore, 1993). Após a seleção da cultivar, foi efetuada a análise de variabilidade considerando todas as variáveis, SEV, TCM, ESP e ICM numa abordagem multivariada (Johnson \& Wichern, 1998). Para tal, ajustouse o modelo $\mathrm{Y}_{\mathrm{ijk}(\text { SEV, TCM, ESP e ICM) }}=\mu+\alpha_{\mathrm{i}}+\beta_{\mathrm{j}(\mathrm{i})}+\mathrm{e}_{\mathrm{ijk}}(\mu=$ média geral, $\alpha_{\mathrm{i}=}$ efeito de município, $\beta_{\mathrm{j}(\mathrm{i})}=$ efeito de isolados aninhados dentro de município e $\mathrm{e}_{\mathrm{ijk}}=$ erro experimental), com o procedimento PROC GLM, opção MANOVA, do programa SAS.

\section{RESULTADOS}

Todos os 53 isolados de $M$. roridum foram patogênicos às cultivares AF-682 e Orange Flesh, e causaram sintomas típicos de cancro no colo, com exceção do isolado CMM627 que não foi patogênico à cultivar Orange Flesh (Tabela 1). Com as análises univariadas, foi possível a distinção de diferentes grupos de isolados pelo teste de agrupamento de Scott-Knott. Com base na SEV foram distinguidos seis grupos de isolados inoculados na cultivar AF-682 e oito na cultivar Orange Flesh (Tabela 1). Os isolados de M. roridum integraram diferentes grupos quando consideradas as duas cultivares de meloeiro. Os valores da SEV variaram entre 1,0 e $96,9 \%$ em 'AF-682' e entre 0,0 e 90,6\% em 'Orange Flesh'. Valores de SEV superiores a 70\% foram registrados por $34,0 \%$ dos isolados na cultivar AF-682, enquanto somente $5,7 \%$ dos isolados induziram severidade inferior a $30 \%$. Por outro lado, valores de SEV superiores a $70 \%$ foram registrados em 'Orange Flesh' por apenas 5,7\% dos isolados e valores inferiores a $30 \%$ foram induzidos por $22,6 \%$ dos isolados (Tabela 1).

Os isolados de $M$. roridum não diferiram quanto à TCM, mas quando consideradas as variáveis ESP e ICM foram formados quatro e três grupos distintos de isolados, respectivamente (Tabela 1). A maioria dos isolados apresentou abundante esporulação, sendo que 92,4\% apresentaram esporulação superior a $1 \times 10^{6}$ conídios $/ \mathrm{mL}$. Todos os isolados foram sensíveis ao fungicida fluazinam, com inibições do crescimento micelial superiores a $50 \%$. Não foram constatadas correlações significativas $(P>0,05)$ entre os valores de SEV nas cultivares AF-682 e Orange Flesh. De maneira similar, não houve correlação entre as variáveis TCM, ESP e ICM, bem como dessas com a SEV nas duas cultivares.

Pela análise dos componentes de variância da SEV, não houve efeito do município de origem dos isolados de
M. roridum. Um expressivo percentual da variância da SEV resultou de diferenças entre isolados dentro do município de origem [isolados (município)], representando 22,5\% da variância total. A maior parte da variabilidade foi atribuída à interação isolados dentro de município x cultivar [isolados (município) x cultivar], responsável por $60,0 \%$ da variância total da SEV (Tabela 2). As variâncias decorrentes dos fatores [isolados (município)] e [isolados (município) $\mathrm{x}$ cultivar] foram maiores que a variância residual, bem como foram constatadas diferenças significativas $(\mathrm{P}<0,001)$ entre as duas cultivares de meloeiro (Tabela 2).

$\mathrm{A}$ interação [isolados (município) $\mathrm{x}$ cultivar] foi altamente significativa $(\mathrm{P}<0,0001) \mathrm{e}$, portanto, foi mantida no modelo ajustado aos dados. Uma vez que a interação foi significativa, interessava determinar em qual das cultivares havia maior poder de detectar variabilidade dos isolados. Para tal, foi realizada a análise de boxplots das variáveis medidas para cada uma das cultivares, sendo constatada maior variabilidade dos dados na cultivar Orange Flesh. Portanto, para investigar mais detalhadamente a variabilidade dos isolados, a severidade medida na cultivar Orange Flesh juntamente com as variáveis fisiológicas e a sensibilidade ao fungicida fluazinam foram submetidas à análise de variância multivariada. Pela análise multivariada não se constatou efeito do município de origem dos isolados, porém, houve grande variabilidade $(\mathrm{P}<0,0001)$ entre os isolados de $M$. roridum dentro dos municípios.

\section{DISCUSSÃO}

Com base na severidade da doença, variáveis fisiológicas e sensibilidade ao fungicida fluazinam, constatouse variabilidade entre isolados de $M$. roridum procedentes de diferentes áreas de plantio de meloeiro do Estado do Rio Grande do Norte. O uso de variáveis individuais, na maioria das situações desse estudo, mostrou ser útil na distinção de grupos de isolados de $M$. roridum com similaridade em SEV, capacidade de esporulação (ESP) e sensibilidade ao fungicida fluazinam (ICM). Somente a taxa de crescimento micelial (TCM) não permitiu a distinção de grupos entre os isolados de M. roridum, o que já foi constatado por Cunfer $e t$ al. (1969) em relação a isolados oriundos de meloeiro.

A avaliação da severidade foi muito útil na separação dos isolados de $M$. roridum em diferentes grupos de virulência a meloeiro. Diferenças na virulência entre isolados de $M$. roridum oriundos desse hospedeiro foram previamente constatadas nos EUA (Carter, 1980) e no Brasil (Lima et al., 1997), embora os estudos tenham envolvido um número reduzido de isolados.

A alta sensibilidade dos isolados de $M$. roridum a fluazinam era esperada, pois esse fungicida não tem sido utilizado especificamente para o controle do cancro-demirotécio no Agropólo Mossoró/Assú e a acumulação de mutantes resistentes em populações fúngicas depende, entre outros fatores, da pressão de seleção exercida pela freqüência de aplicação do fungicida (Kendall \& Hollomon, 1998). 
TABELA 2 - Estimativa de efeito médio da cultivar (fator fixo) e dos componentes de variância para os fatores município de origem, isolados de Myrothecium roridum dentro de município [isolados(município)], interação isolados dentro de município x cultivar [isolados(município) x cultivar], e resíduo (fatores aleatórios), para severidade

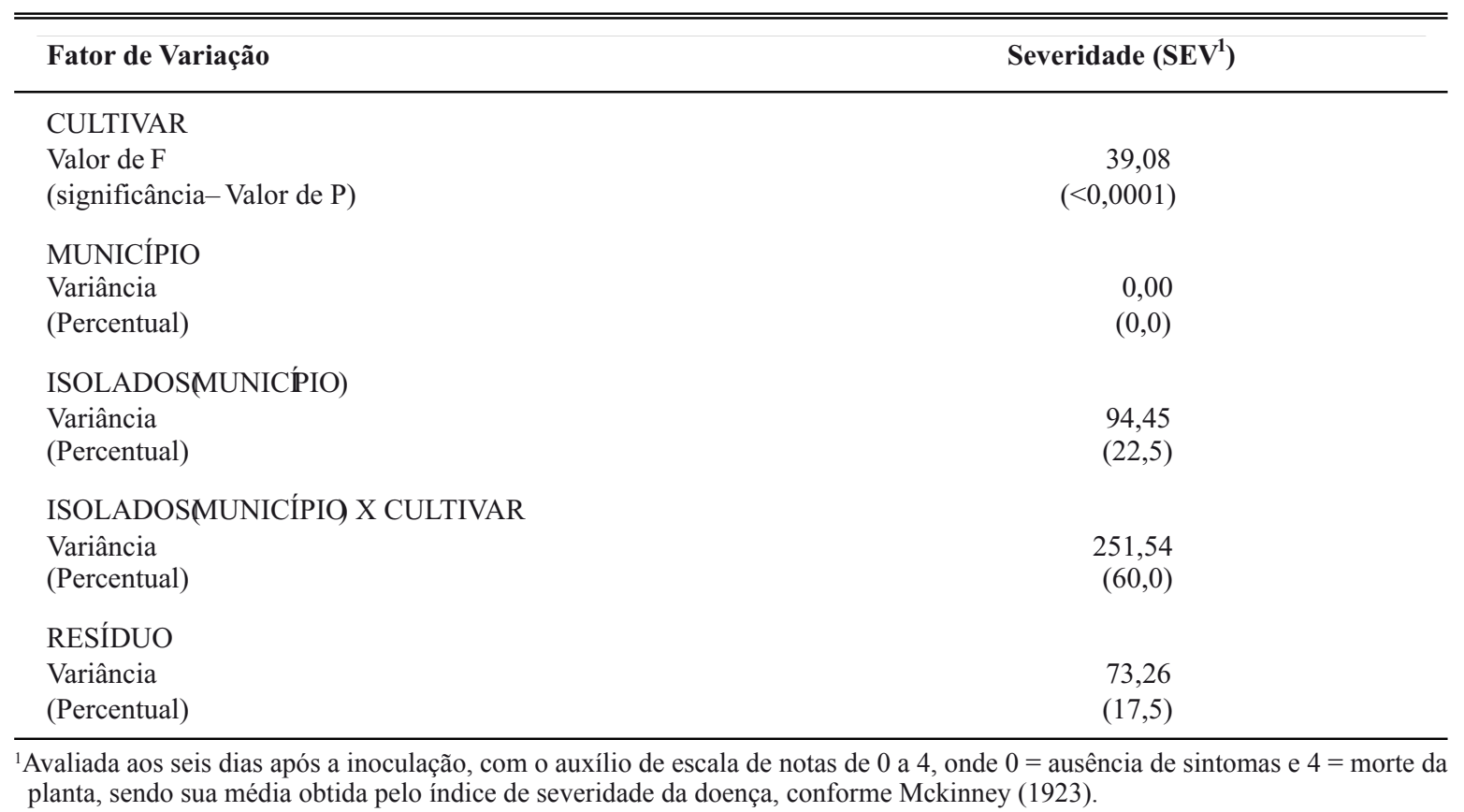

Embora o surgimento de resistência ao fluazinam possa implicar na redução da virulência dos isolados resistentes (Fuchs \& Waard, 1982), não foram verificadas correlações consistentes entre a severidade do cancro-de-mirotécio e a sensibilidade ao fluazinam entre os isolados. Além disso, no presente estudo, a sensibilidade ao fluazinam não esteve associada com a capacidade de crescimento micelial ou esporulação na ausência do fungicida.

A ausência de correlações significativas entre TCM, ESP e ICM dos isolados de $M$. roridum, bem como dessas com a SEV pode indicar que as características são determinadas por diferentes grupos de genes e a população seja espontaneamente recombinada (Caten \& Newton, 2000). Outro aspecto a ser considerado é que as características fisiológicas testadas provavelmente não propiciam qualquer vantagem evolutiva a $M$. roridum, visto que se trata de parasita facultativo com alta capacidade saprofítica (Schroers et al., 1999).

O maior percentual da variância total foi devido à variabilidade constatada entre isolados de $M$. roridum obtidos num mesmo município, sob a influência da cultivar na qual foram inoculados. Portanto, há variabilidade entre os isolados dentro do município de origem e as cultivares AF682 e Orange Flesh diferem quanto aos níveis de resistência. Como apenas uma pequena porcentagem da variabilidade pôde ser atribuída às diferenças entre os municípios de origem dos isolados, não há evidência de diferenciação das populações entre isolados de Baraúna e Mossoró, ou seja, nos dois locais os isolados são igualmente variáveis quanto aos componentes epidemiológicos do cancro-de-mirotécio, indicando que os isolados avaliados constituem uma única população do patógeno.

A diferença dos isolados de $M$. roridum quando inoculados nas duas cultivares de meloeiro permite especular sobre a existência de interação diferencial e, conseqüentemente, a possível ocorrência de raças em populações do patógeno. Esse fato justifica a importância de conhecer melhor a amplitude de variação na virulência dos isolados de $M$. roridum e a necessidade de utilizar genótipos diferenciadores para melhor entender esta interação, colaborando assim com informações pertinentes em futuros programas de melhoramento visando a resistência à doença.

Embora as informações sobre o patossistema $M$. roridum-meloeiro ainda sejam escassas, é possível afirmar que há alta variabilidade patogênica entre os isolados deste fungo. As causas do surgimento da variabilidade entre os isolados do patógeno permanecem desconhecidas. No entanto, a variabilidade pode estar associada à adaptação às diferentes cultivares de meloeiro, pois nos campos de produção do Agropólo Mossoró/Assú são plantadas diversas cultivares, com alta suscetibilidade ao cancro-de-mirotécio (Noronha et al., 2006). Outra hipótese a ser considerada é a ocorrência de eventos de recombinação, por fusão vegetativa com populações filogeneticamente relacionadas (Samuels \& Seifert, 1995). Embora até o momento não seja conhecido o teleomorfo de $M$. roridum, a hipótese de a variabilidade ser decorrente de reprodução sexual não pode ser descartada, pois Stephanonectria keithii (Berk. \& 
Br.) Schroers \& Samuels e Nectria pityrodes (Montagne) Montagne são teleomorfos que foram associados a estádios anamórficos com características morfológicas semelhantes às do gênero Myrothecium (Schroers et al., 1999). O conhecimento da presença de variabilidade em populações de $M$. roridum poderá ser útil para otimizar o manejo de genes de resistência, para maximizar a expectativa de uso de fungicidas e minimizar as perdas que resultam da redução de eficiência desses métodos de controle.

\section{AGRADECIMENTOS}

Os autores expressam seus agradecimentos ao Conselho Nacional de Desenvolvimento Científico e Tecnológico - CNPq pelo financiamento (Processo no. 620111/04-6)

\section{REFERÊNCIAS BIBLIOGRÁFICAS}

Bruton BD (1996) Crater rot. In: Zitter TA, Hopkins DL, Thomas CE (Eds.) Compendium of Cucurbit Diseases. Saint Paul MN. APS Press. pp. 49-50.

Bruton BD (1998) Soilborne diseases in cucurbitaceae: pathogen virulence and host resistance. In: McCreight J (Ed.) Cucurbitaceae 98. Alexandria. International Society of Horticultural Science. pp. 143-166.

Carter WW (1980) Incidence and control of Myrothecium roridum on cantaloupes in relation to time of fungicide application. Plant Disease 64:872-874.

Caten CE, Newton AC (2000) Variation in cultural characteristics, pathogenicity, vegetative compatibility and electrophoretic karyotipe within field populations of Stagonospora nodorum. Plant Pathology 49:219-226.

Chitarra LG, Meyer MC (2004) Novo e sem controle. Cultivar Hortaliças e Frutas 19:16-18.

Cunfer BM, Grahem JH, Lukezic FL (1969) Studies on the biology of Myrothecium roridum and $M$. verrucaria. Phytopathology 59:1306-1309.

Domsch KW, Gams W, Anderson TH (1980) Compendium of Soil Fungi. London. Academic Press. v.1.

Drake GN (1980) Effect of Myrothecium roridum on the germination of cotton seeds. Indian Phytopathology 33:591-593.

FNP. Agrianual 2008 - Anuário da Agricultura Brasileira. São Paulo. Instituto FNP. 2008.

Fuchs A, Waard MA (1982) Resistance to ergosterol-biosynthesis inhibitors. I. Chemistry and phenomenological aspects. In: Dekker J, Georgopoulos SG (Eds.) Fungicide Resistance in Crop Protection. Wageningen. Centre for Agricultural Publishing and Documentation. pp. 71-86.
Johnson RA, Wichern DW (1998) Applied Multivaried Statistical Analysis. Prentice Hall. New Jersey.

Kendall SJ, Hollomon DW (1998) Fungicide resistance. In: Hutson DH, Miyamoto J (Eds.) Fungicidal Activity. New York. John Wiley \& Sons. pp. 87-108.

Lima GSA, Oliveira SMA, Bezerra Neto E, Menezes M (1997) Reação de cultivares de melão a isolados de Myrothecium roridum. Summa Phytopathologica 23:135-139.

Littell RC, Milliken GA, Stroup WW, Wolfinger RD (1996) SAS System for Mixed Models. SAS Institute. Cary.

MAPA. AGROFIT - Sistema de Agrotóxicos Fitossanitários. Brasília. Ministério da Agricultura, Pecuária e Abastecimento, 2008. Disponível em: < http://extranet.agricultura.gov.br/agrofit_ cons/principal_agrofit_cons>. Acesso em: 10 nov 2008.

Mcdonald BA, Linde C (2002) Pathogen population genetics, evolutionary potential, and durable resistance. Annual Review of Phytopathology 40:349-379.

Mckinney HH (1923) Influence of soil temperature and moisture on infection of wheat seedlings by Helminthosporium sativum. Journal of Agricultural Research 26:195-218.

Neter J, Wasserman W, Kutner MH (1990) Applied Linear Statistical Models. $3^{\text {rd }}$ ed. Boston MS. Irwin.

Nguyen TH, Mathur SB, Neergaard P (1973) Seed-borne species of Myrothecium and their pathogenic potential. Transactions of the British Mycological Society 61:347-354.

Noronha MA, Michereff SJ, Xavier Filha MS, Moreira PAA, Reis A, Sales Junior R (2006) Reação de genótipos de meloeiro a Myrothecium roridum. Horticultura Brasileira 24:495-498.

Peck R, Devore JL (1993) Statistics: Exploration and Analysis of Data. $2^{\text {nd }}$ ed., Duxbury Press. Belmont.

Rego AM, Carrijo IV (2000) Doenças das cucurbitáceas. In: Vale FXR, Zambolim L, Costa H (Eds.) Controle de Doenças de Plantas - Hortaliças. Viçosa MG. Universidade Federal de Viçosa. v. 2. pp. 535-598.

Samuels GJ, Seifert KA (1995) The impact of molecular characters on systematics of filamentous ascomycetes. Annual Review of Phytopathology 33:35-67.

Santos AA, Pinheiro Neto LG (2004) Podridão-de-Esclerócio do Melão no Estado do Ceará. Fortaleza. Embrapa Agroindústria Tropical.

Schroers HJ, Samuels G, Gams W (1999) Stephanonectria, a new genus of the Hypocreales (Bionectriaceae), and its sporodochial anamorph. Sydowia 51:114-126.

Silva DMW, Menezes M, Oliveira SMA, Pereira GF (1996) Ocorrência de Myrothecium roridum em melão em Mossoró, Rio Grande do Norte. Fitopatologia Brasileira 21:519. (Resumo)

Viana FMP, Santos AA, Freire FCO, Cardoso JE, Vidal JC (2001) Recomendações para o Controle das Principais Doenças que Afetam a Cultura do Melão na Região Nordeste. Fortaleza CE. Embrapa Agroindústria Tropical. 